\title{
RAPID ENZYMATIC DEBRIDEMENT OF DEEP FACIAL BURNS IN A PATIENT WITH SEVERE INHALATION INJURY A CASE REPORT
}

\begin{tabular}{|c|c|}
\hline & Ferančíková N., Šarkőzyová N., Koller J. \\
\hline & Department of Burns and Reconstructive Surgery , \\
\hline
\end{tabular}

\section{Background}

Deep facial burns are often combined with severe inhalation injury. The current method of choice for burn eschar removal is tangential excision. However, during tangential excision also viable tissues with good healing capacity are removed, which is important particularly in functional areas as are the face and hands.

\section{Objectives}

To assess the off-label use of rapid enzymatic debridement of deep facial burns associated with severe inhalation injury.

\section{History of Case Report}

- A 53-year-old female patient sustained 16\% TBSAB (Total Body Surface Area Burns) caused by fire to face, neck, trunk, both hands and right thigh associated with severe inhalation trauma.

- The burn depth was diagnosed clinically as mixed deep dermal/third degree of $12 \%$ TBSAB and superficial of $4 \%$ TBSAB.

\section{Clinical Procedure}

- Enzymatic debridement of deep burn areas at face, neck and both hands (8\%TBSA) was performed by bromelain derived proteolytic enzymes mixture gel (NexoBrid, MediWound) starting 41 hours post injury. The area of both eyes has been protected by a thick layer of sterile vaseline and gauze coverage.

- All the debrided wounds have been covered temporarily by freshfrozen porcine xenografts.

- Full thickness skin injury areas were closed by split thickness autografts.

- Deep dermal areas did heal under xenograft coverage conservatively.
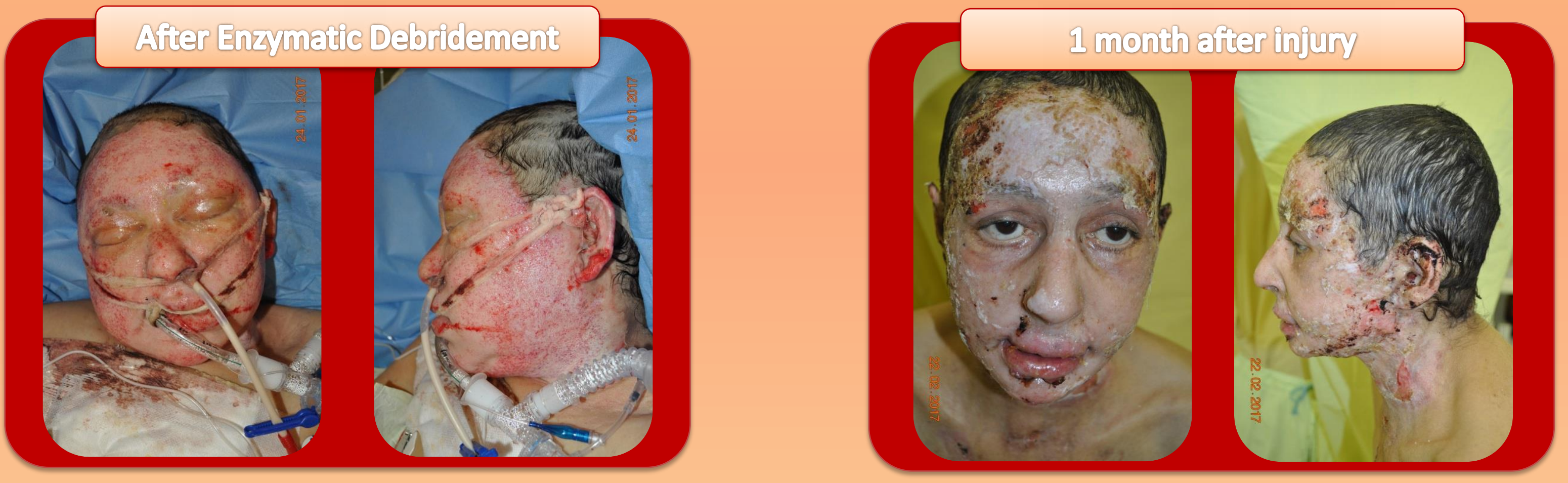

\section{Results}

Single debridement efficacy was $95 \%$ on the face, neck and trunk and $90 \%$ on both hands. Healing by epithelization under xenografts of most of the wounds including face area was achieved within 5 weeks. Only 2,5\% TBSA of the debrided areas on both hands and neck required autografts.

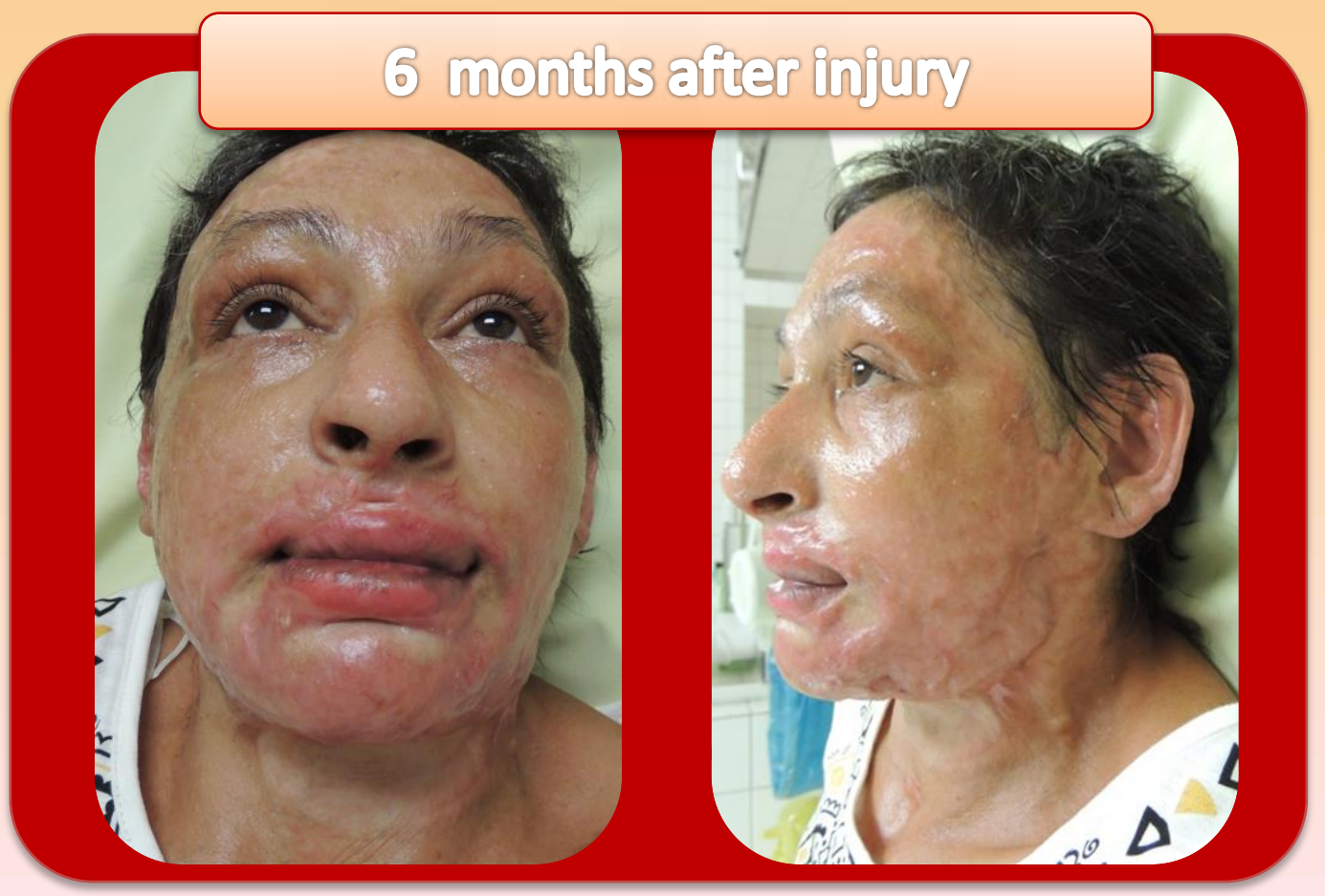

\section{Conclusions}

- Deep facial burns are often combined with severe inhalation injury.

- In cases of indeterminate burns enzymatic debridement, which is highly selective removing only necrotic tissues and saving viable tissues showed to be of advantage compared to tangential excision, moreover, facilitating the exact burn diagnosis as well.

- Enzymatic debridement proved to be safe and effective on the face in a high-risk patient with severe inhalation injury and unstable circulation as an alternative to tangential excision. 